\title{
60 years of ideas, evidence, and impact
}

Population Council

Follow this and additional works at: https://knowledgecommons.popcouncil.org/

series_newsletters_momentum

How does access to this work benefit you? Let us know!

\section{Recommended Citation}

"60 years of ideas, evidence, and impact," Momentum newsletter. New York: Population Council, 2012. 

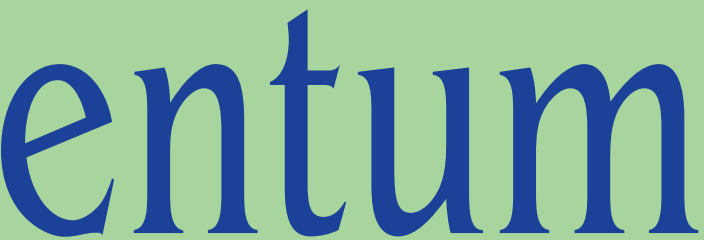

NOVEMBER 2012

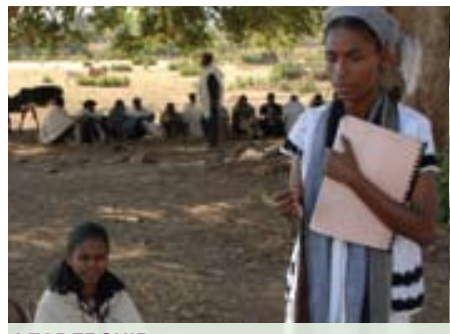

LEADERSHIP

CHANGING THE WAY THE WORLD THINKS

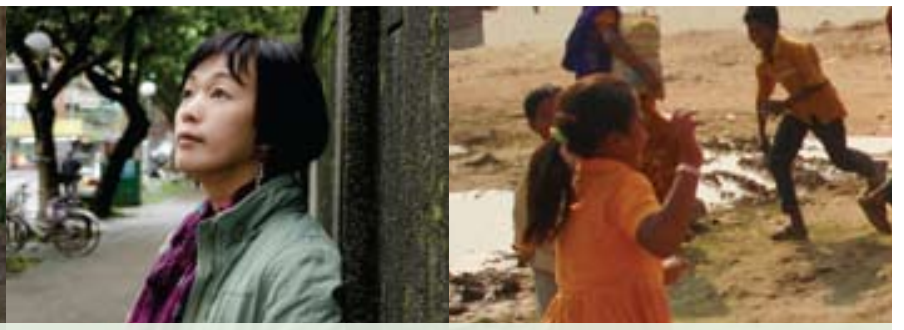

ADVANCING \& SHARING KNOWLEDGE

SHAPING POLICY

FAMILY PLANNING IN TAIWAN

HEALTH CARE IN BANGLADESH
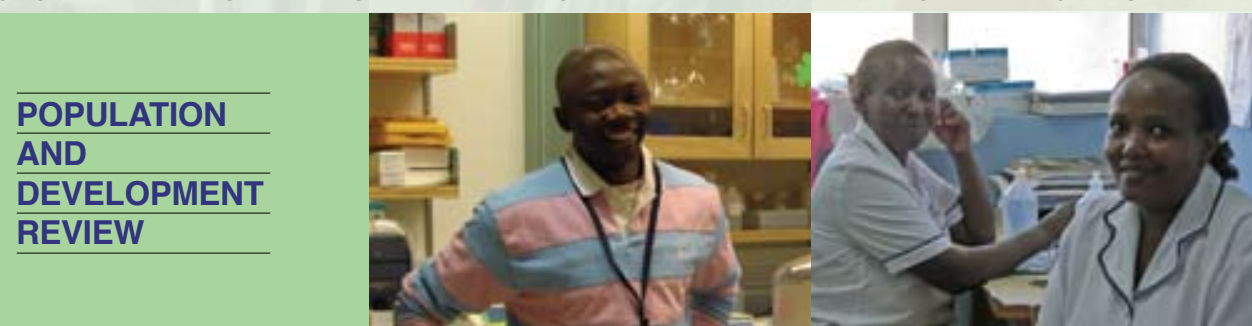

ADVANCING \& SHARING KNOWLEDGE PUBLISHED RESEARCH

BUILDING RESEARCH CAPACITY INSPIRING FUTURE LEADERS
DELIVERING SOLUTIONS DEVELOPING EFFECTIVE CONTRACEPTIVES

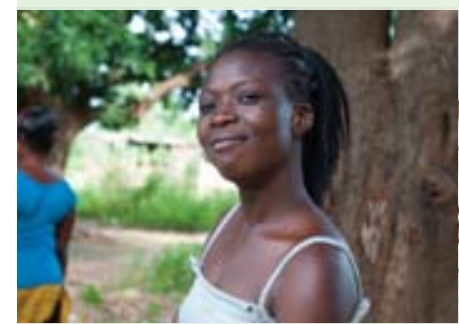

SHAPING POLICY IMPROVING GIRLS' LIVELIHOODS

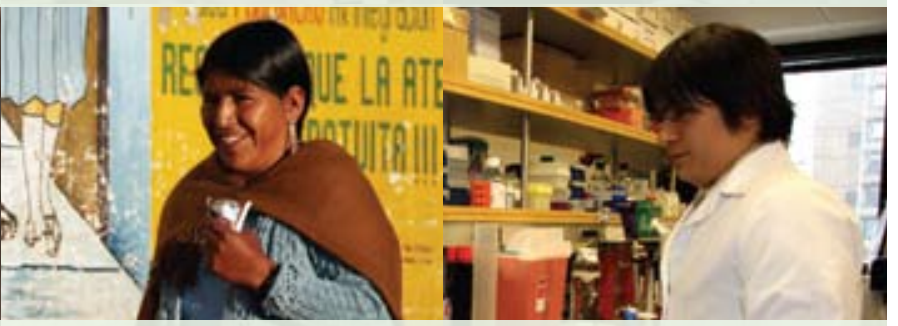

IMPROVING PROGRAMS

ADVANCING \& SHARING KNOWLEDGE

For more than 60 years, the Population Council has been generating ideas, providing evidence, and delivering solutions that have improved the lives of hundreds of millions of people. In this issue, we present stories and a timeline about our impact.

$\begin{array}{lll}\text { E } & \text { I D EA S } \\ \text { A } \\ \text { R } \\ \text { S }\end{array}$




\section{YEARS OF IDEAS, EVIDENCE, AND IMPACT}

\section{2}

John D. Rockefeller 3rd convenes distinguished scientists in

Williamsburg, Virginia, under the auspices of the National Academy of Sciences, to begin the search for a better understanding of population issues. Thereafter, he establishes the Population Council as an independent nonprofit

organization and serves as its first president.

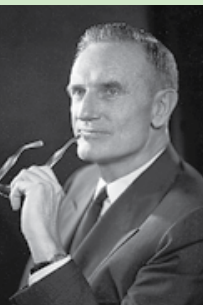

\section{0s/1960s}

Council begins providing

grants to researchers and

institutions around the world

for studies of knowledge,

attitudes, and practices

related to family planning.

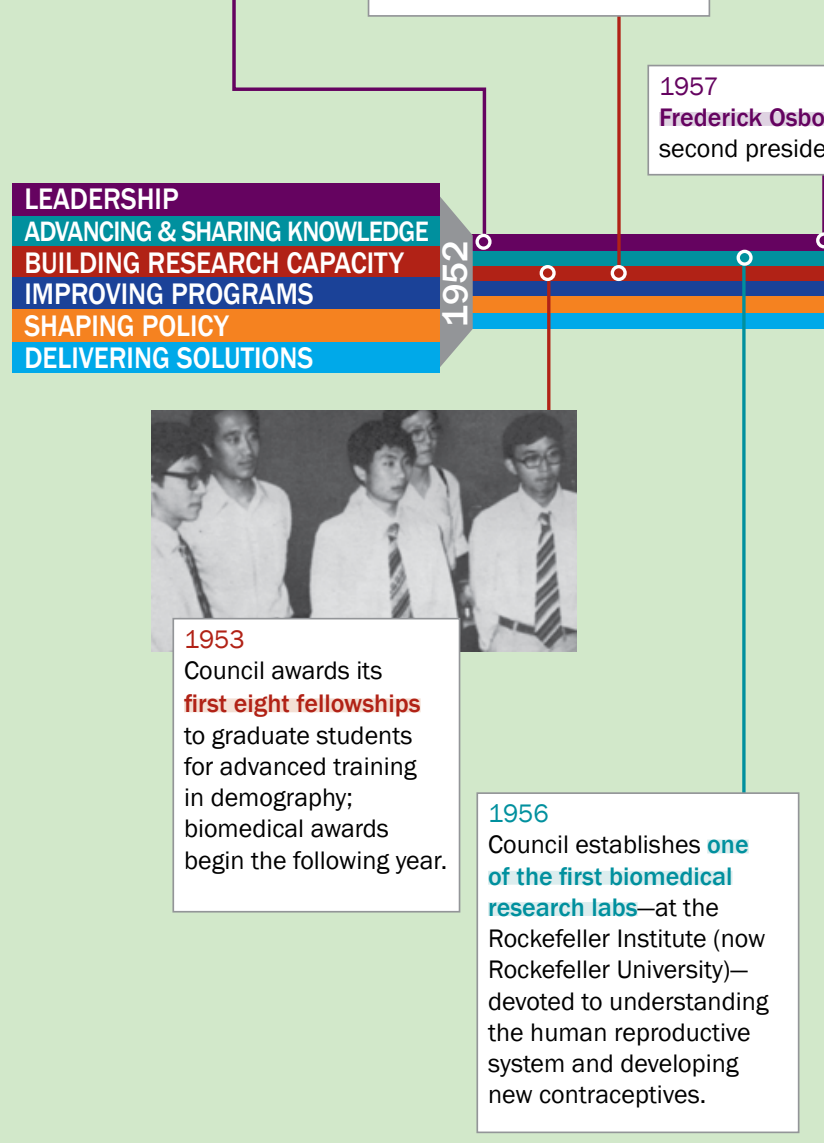

Council hosts the first international conference on intrauterine devices (IUDs) to consolidate knowledge and spur interest in the development of new devices.

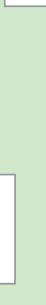

1959

Frank W. Notestein, third president

\section{LEADERSHIP}

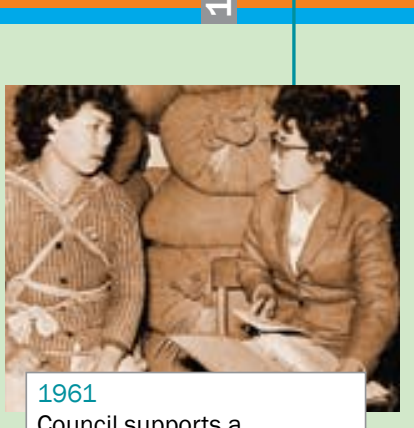

Council supports a pioneering family planning

Taiwan to increase access to

information and services.

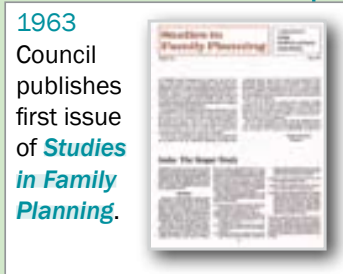
study in Taichung City,

\section{6}

Council initiates the International Postpartum Project to determine the feasibility of providing family planning services in family planning services in hospitals following child ibirth; more than 250 hospitals in 21 countries participate and more than a million women receive their desired family planning method.

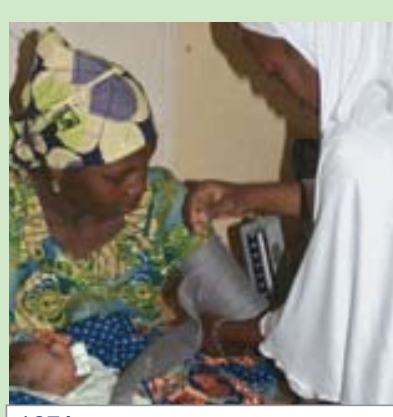

Council develops successful maternal and child health-based family planning projects in Indonesia, Nigeria, the Philippines, and Turkey, changing the way an think about integr family planning in rural areas. Africa to strengthen demographic course offerings and research capability.
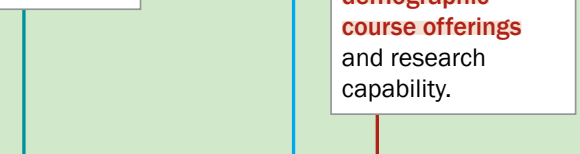

\section{8}

Bernard Berelson, fourth president
1976

George Zeidenstein, fifth
1978

Demographer John Bongaarts develops a framework for analyzing the proximate determinants of fertility-a simple model that explains how events like marriage, childbirth, and abortion affect fertility-one of the most widely used tools for analyzing fertility change.

that smoking

cigarettes

while using oral

contraceptives

increases

women's risk

of heart attack

stroke, and death,

particularly for

those 40 years

and older.

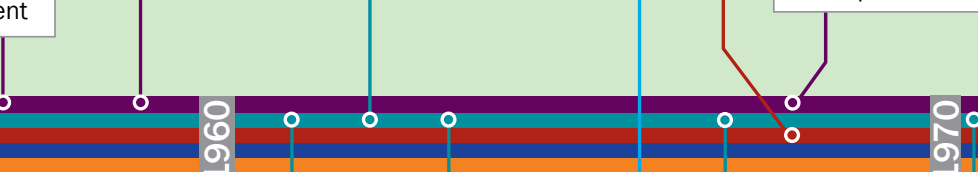
leaders think about integrating maternal and child healthcare and

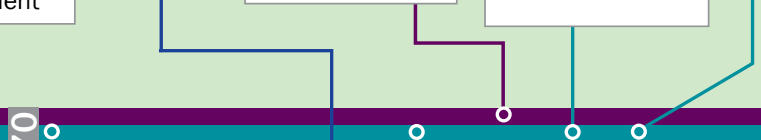

\section{7}

Council collaborates with Walt Disney to produce a 10-minute educational cartoon, Family Planning, translated into 25 languages.

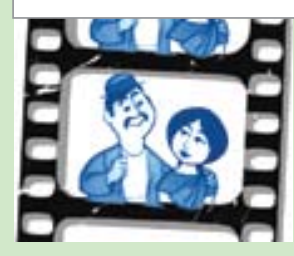
1970 Council forms the International Committee for Contraception Research, a Research, a researchers who conduct clinical trials to test the safety, efficacy, and acceptability of Council-developed products.
1975

Council publishes first issue of Population and Development Review.
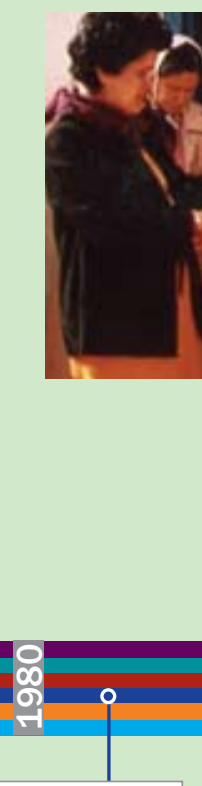

1981
1976

U.S. Food and Drug Administration

approves the

Council's Copper

T200 IUD, the

first-ever New

Drug Application

sponsored by a

nonprofit research

organization.

\section{7}

Council begins its

long-term collaboration

with ICDDR, B to

document the benefits

of family planning in

Bangladesh. large-scale

operations

research to

research to

improve the

quality, and

sustainability of

family planning

services in Asia.

1978

Council establishes Middle East Research Awards program to strengthen the skills of talented young social scientists. 
PIONEERING ACCESS TO FAMILY PLANNING INFORMATION AND SERVICES

\section{2}

World population increased dramatically in the aftermath of World War II, largely because of declining mortality. Fertility remained high, and governments in developing countries began to consider rapid population growth an obstacle to economic and social development.

At the time, international aid agencies did not provide contraceptives or support family planning programs. United Nations agencies collected and analyzed population data, but did not use those data to inform program and policy development. Foundations and schools of public health did not have population programs.

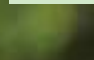

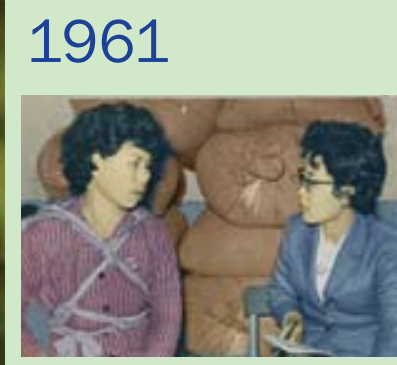

With industrial modernization in Taiwan well underway, couples surveyed in the early 1960s expressed a desire for smaller families but did not have access to family planning information and services.

In 1961, the Population Council partnered with the government of Taiwan to establish a Population Studies Center in Taichung City. With the Council's technical advice, the Center launched a two-year study to evaluate strategies for providing family planning information and services in three areas of the city. Information about family planning was disseminated through posters, community meetings, letters, and home visits. Researchers recorded which strategies were the most effective. Participants in the study areas were offered wide range of contraceptive methods, including intrauterine devices (IUDs), oral contraceptives, and traditional methods. Contraceptive use increased substantially, with 80 percent of women in the study area preferring the IUD over other methods. Researchers also documented a significant reduction of fertility in the study areas.

\section{8}

The Council continued to support family planning activities that spread to the rest of Taiwan. Following an accelerating decline in birth rates, in 1968 Taiwan adopted an official family planning policy Between 1965 and 1970 , contraceptive use increased from 24 percent to 44 percent, and the proportion of users among couples wanting no more children increased from 39 to 64 percent. Population growth decreased from nearly 3 percent annually around 1960 to reach the replacement level of 2.1 children per woman in 1984

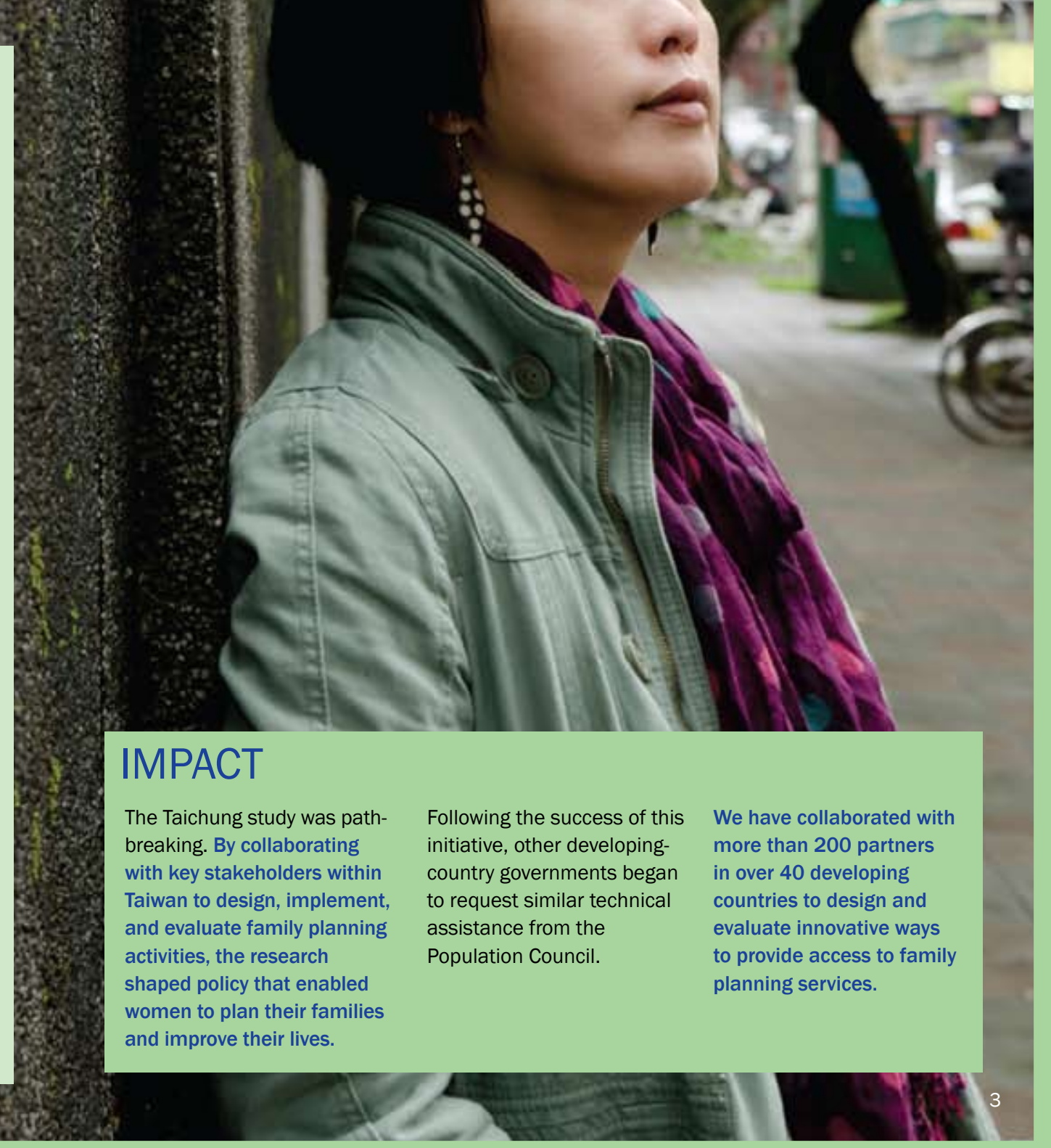




\section{GENERATING EVIDENCE TO GUIDE NATIONAL POLICY IN BANGLADESH}

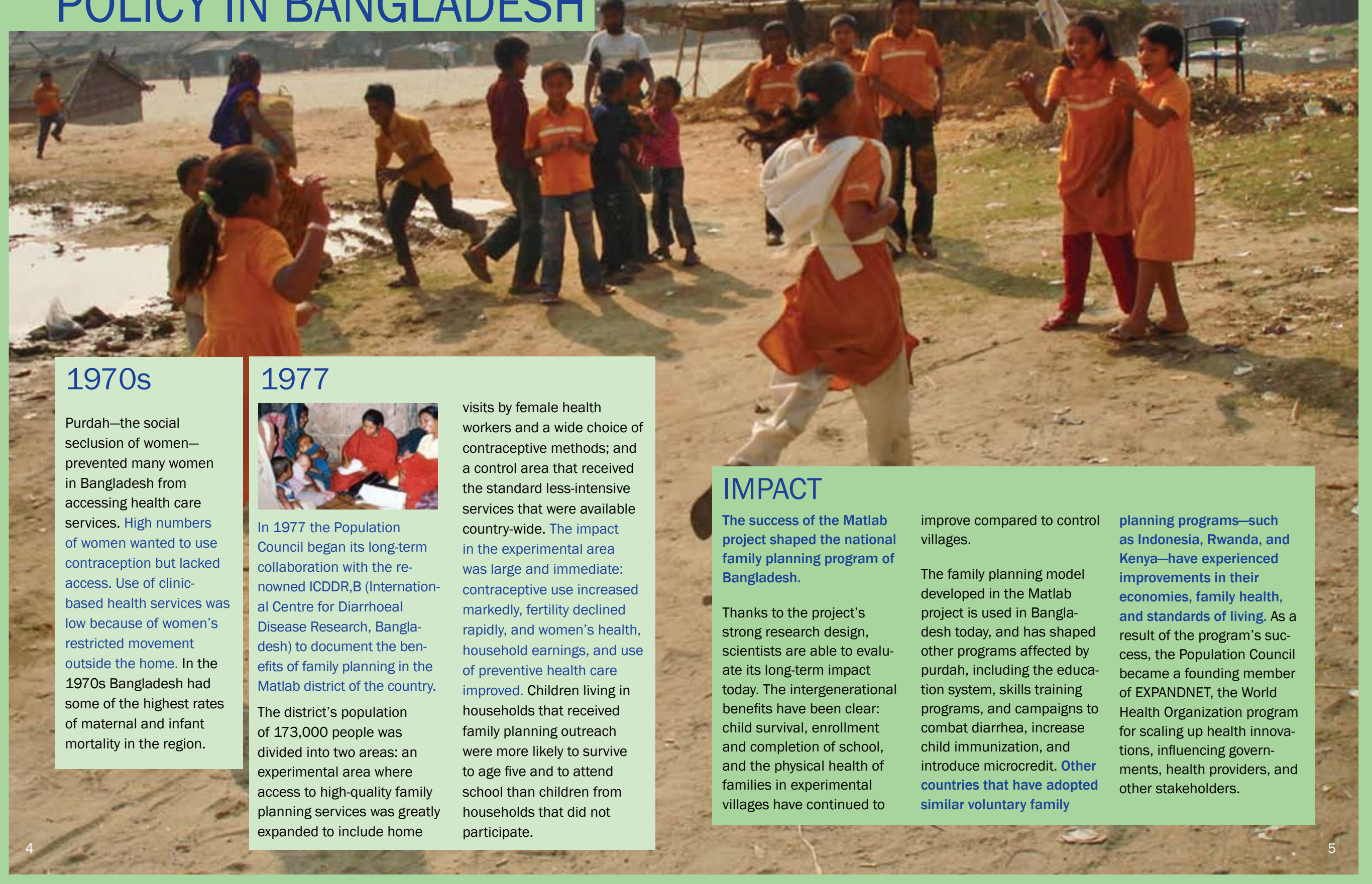




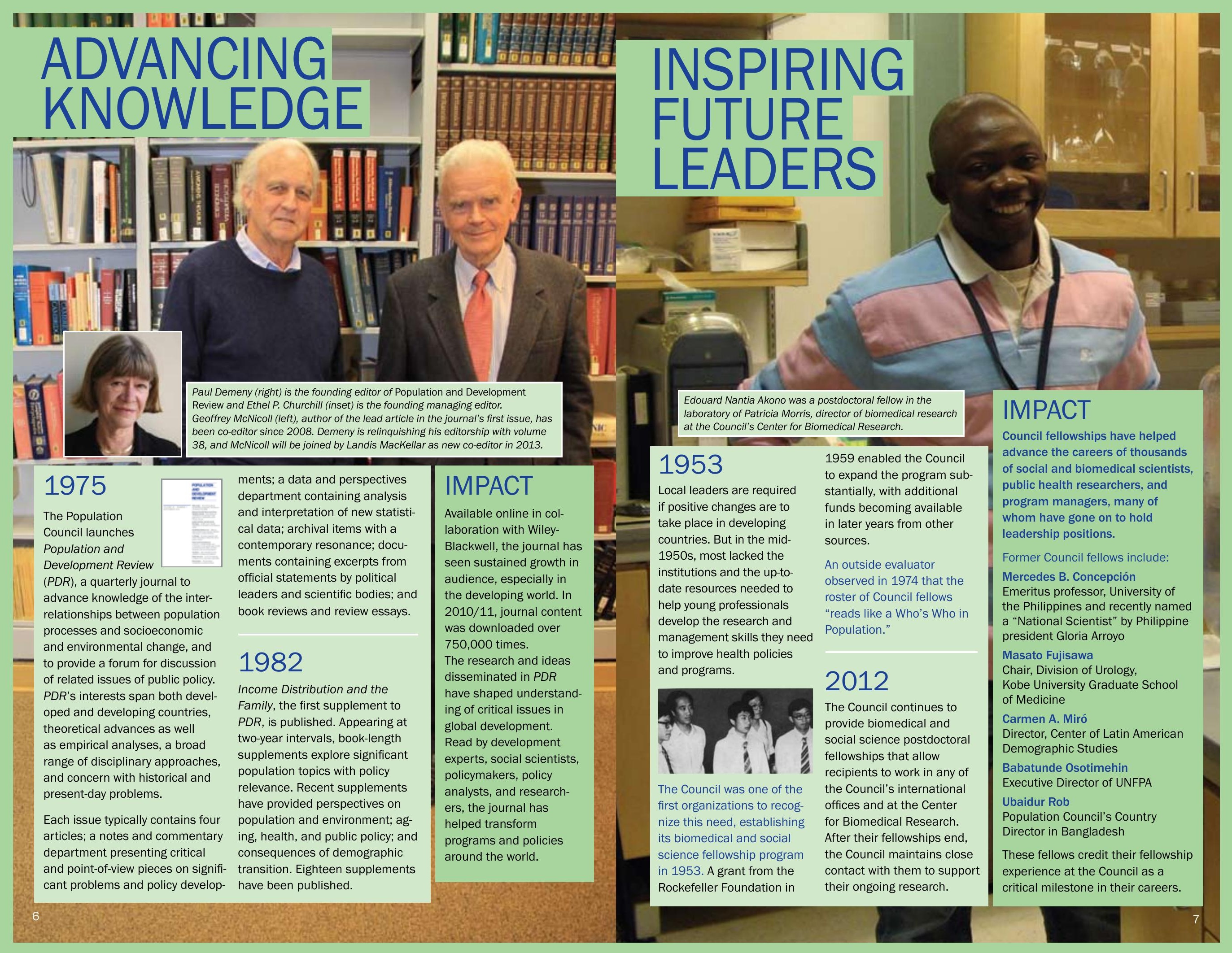




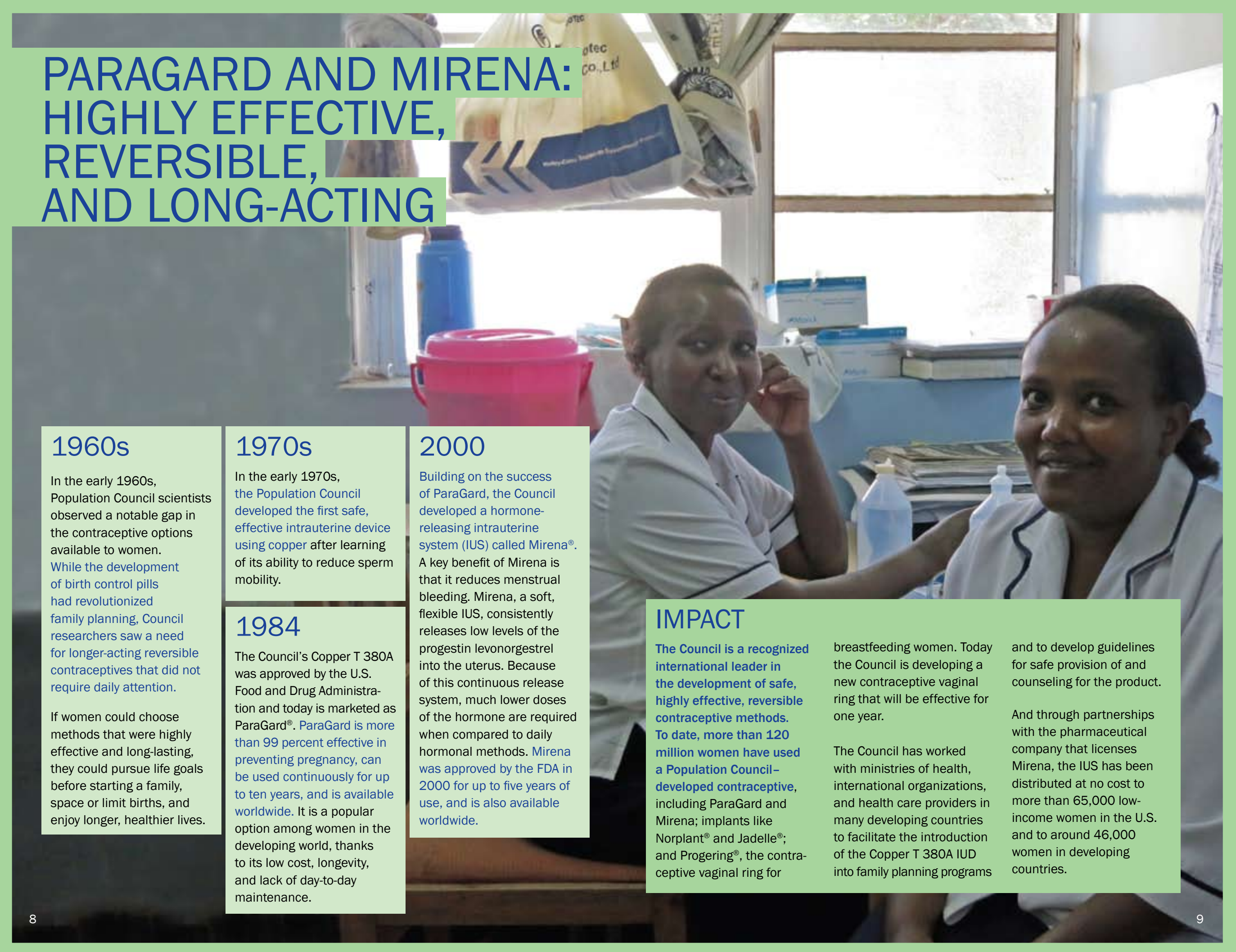




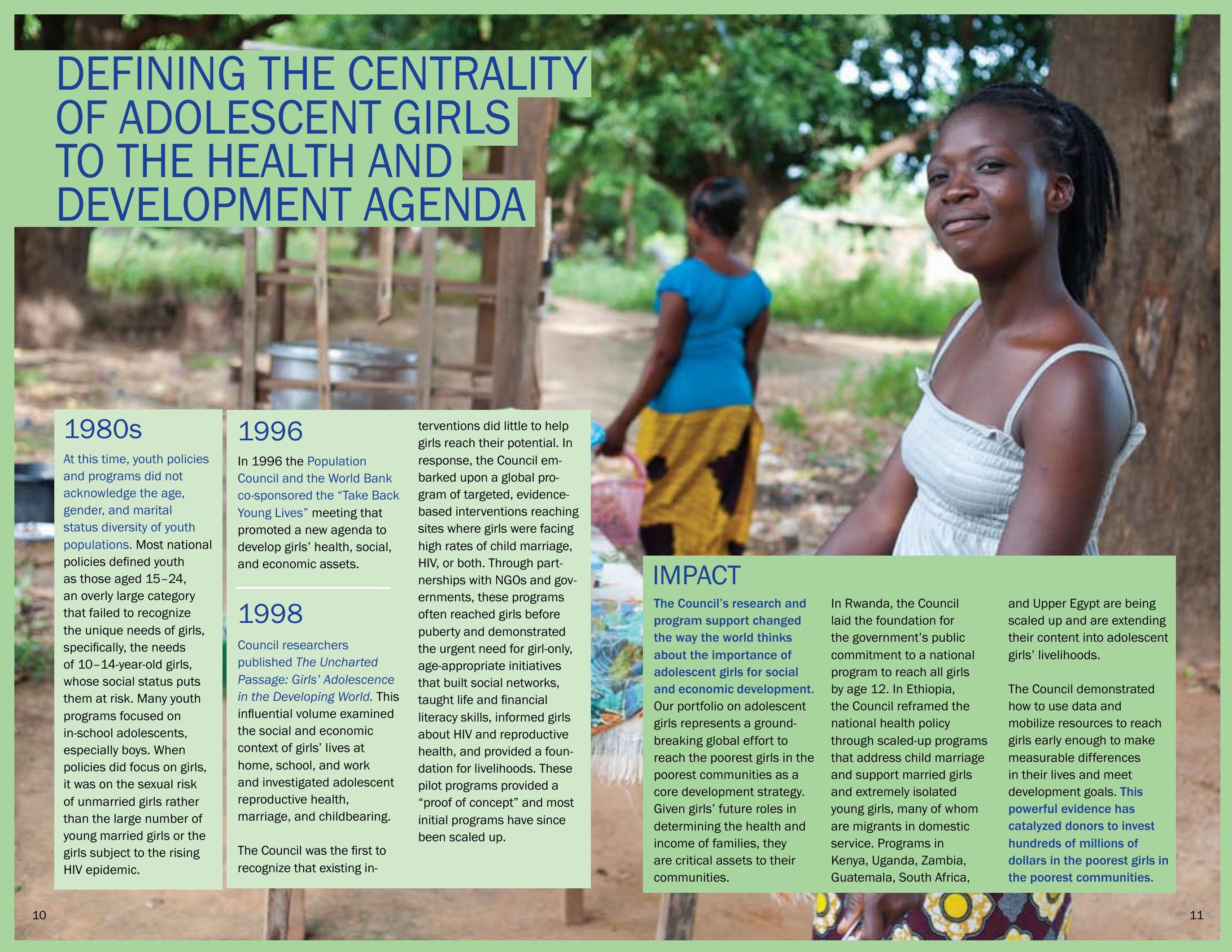




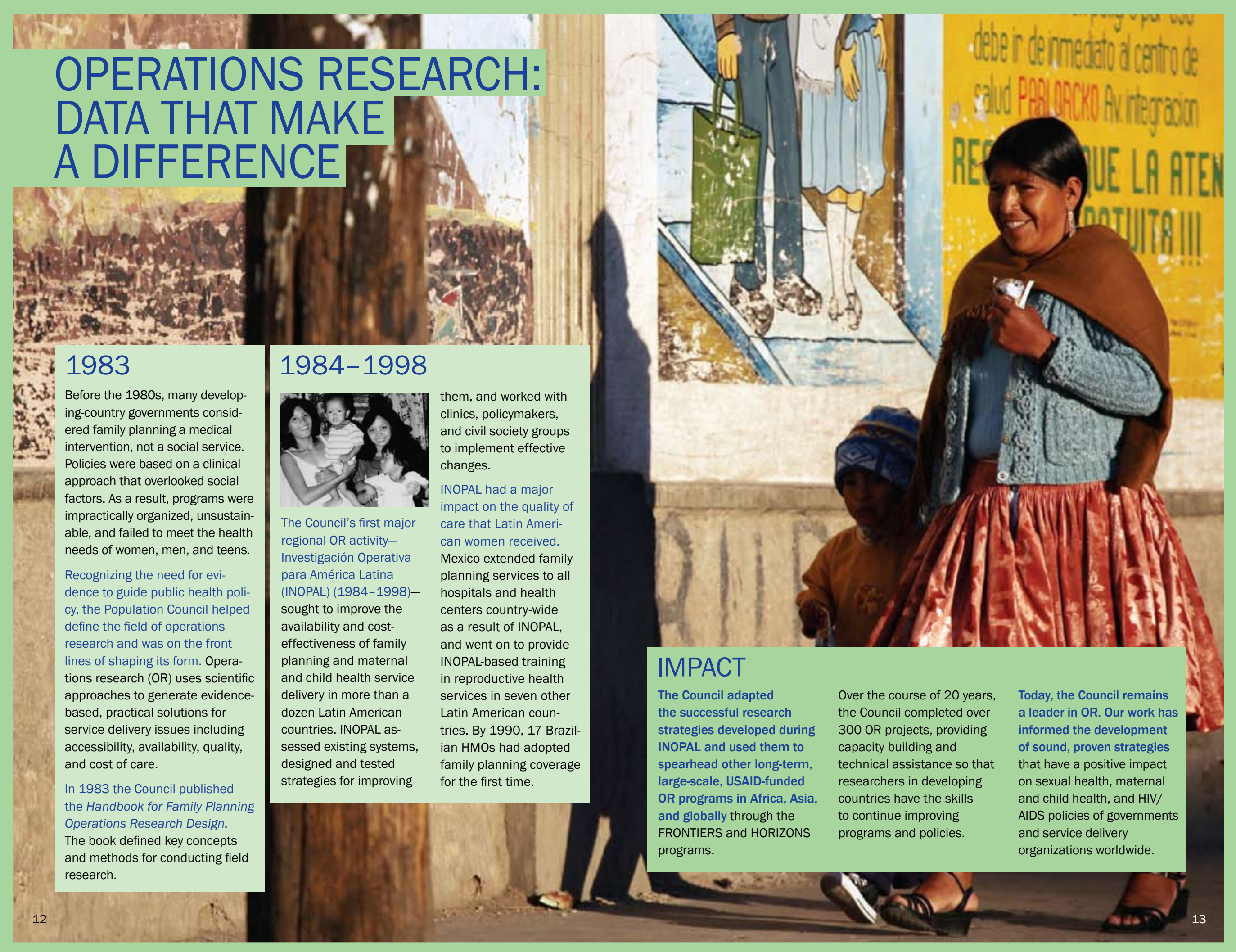




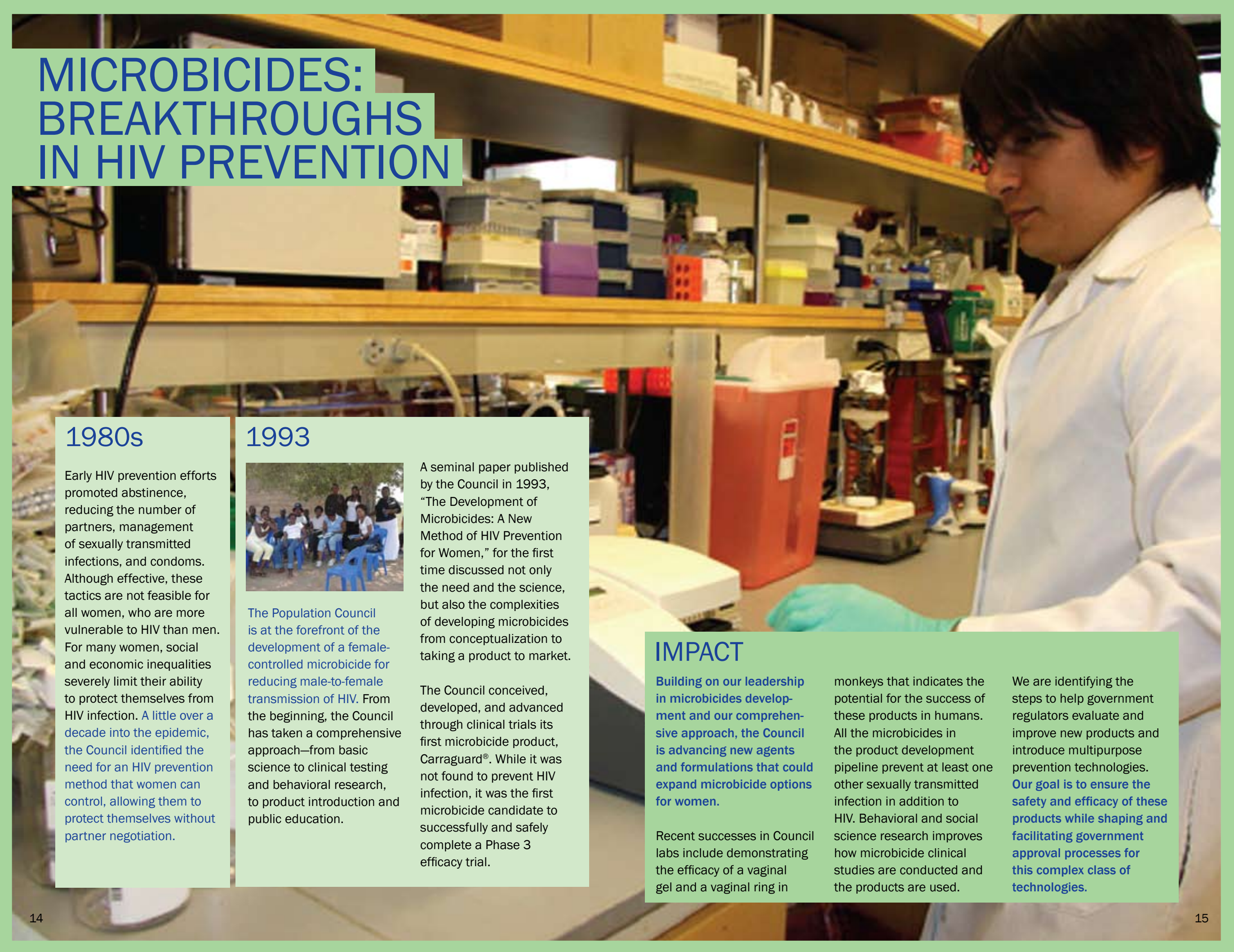




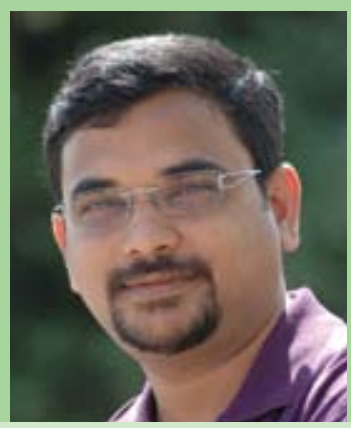

Your background is originally in biostatistics. How did you end up studying HIV and public health?

In India, you are constantly reminded of the importance of public health. The severe poverty faced by many of our citizens-and our country's rapid population growth-underscore this every day.

On a personal level, I was drawn to the field of HIV after losing my cousin and close friend to HIV-related illness in 1996. Few family members attended his funeral due to stigma and fear, and my cousin's family was traumatized. Shortly after losing my cousin, I also lost a number of people from my hometown to the disease.

These incidents affected me profoundly. I decided to shift the focus of my graduate work to public health, and my background in biostatistics allowed me to take a quantitative approach to work on communicable diseases. I completed my $\mathrm{PhD}$ in the area of HIV and tuberculosis morbidity and mortality.

What was your proudest professional moment?

I'm proud to be called the "Migration Man!" As a result of my research on migration and HIV acquisition, we now understand that migration is the number one factor in the spread of HIV in India.

The research I conducted with Population Counci colleagues found that migrant workers were four times more likely to contract HIV than nonmigrant workers, and that prevention programs needed to reach migrants not only at their destination point, but also at their place of origin and the transit points along their way. Our work also has shown the need to build the capacity of local infrastructure to implement coordinated interventions using existing structural resources for long-term program sustainability. HIV funds in India are limited, so many were concerned that this approach would be too expensive with little return on investment. But the Population Council had the hard evidence to show its worth in light of areas. Thanks to our research, the government has completely altered its approach. Seeing this change is my lifetime achievement so far.

\section{What sets the Council apart?}

Before joining the Population Council in 2006, I worked for a government institute and wanted to join the Council because the Council's work informs policies and programs and its staff thinks 10 years ahead when it comes to research and public health concerns. We have foresight and generate evidence and exceptional research to change the way governments, international organizations, and NGOs think about critical health and development issues. Our work on HIV and migrant workers is a perfect example: when we started in 2005, no one paid attention to migration and the health of migrant workers. Now migration will be the focus of the next national AIDS program. Policymakers and donors recognize the value of the high-quality research the Council delivers, and our results deliver solutions that improve lives. growing numbers of infections in the newer

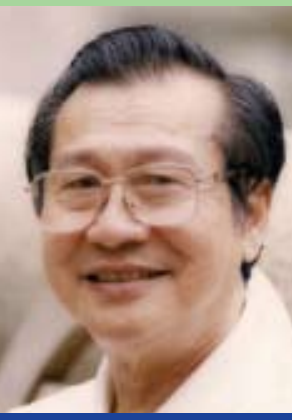

WHY I GIVE TO THE POPULATION COUNCIL

I was born in a rural area of Taiwan. At university, I planned to study agricultural economics to help farmers. But during my studies, a geography professor showed me that agricultural development was not keeping pace with fast population growth. From that moment, became increasingly interested in the effects of population on individual health and societal development

In 1961, with funding from the Population Council, a population studies center was established in Taichung City under the Health Department of Taiwan Provincial Government. I was fortunate to have the opportunity to work with the Center on the famous "Taichung Study" (see page 2), which not only demonstrated that family planning was acceptable, but also shaped national family planning policies and changed lives. Once the Taichung Study was completed, the Population Council provided me with a two year fellowship to the University of Michigan's Population Studies Center to help analyze and translate the Taichung survey for wide dissemination.
After the completion of Taiwan's demographic transition in the 1980s, I was invited to join a commission of the Taiwan President's Cabinet, where today I oversee research, development, and evaluation of the government's policies and programs. While leading Taiwan's family planning program, I have been lucky to go to many developing countries to see their family planning programs and in turn invite them to Taiwan. I teach demography at the National Taiwan University. None of this would have happened to me were it not for the fellowship from the Population Council.

I give to the Council because I owe much to the Council for my career. I have worked for decades to promote family planning in Taiwan and have seen much progress in the quality of people's lives in my country. Policymakers, program managers, and others concerned with population and development issues turn to the Population Council for rigorous research results that change national policies and programs and improve lives. The Council is one of the most important organizations to help humankind live more happily with good health. 


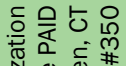

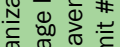

त्ञ

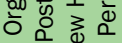

जे

힘

ㅎํㄴ 